\title{
The effect of focus on lexical tones in Vietnamese
}

\author{
Stefanie Jannedy \\ Center of General Linguistics (ZAS), Berlin, Germany \\ https://doi.org/10.36505/ExLing-2008/02/0029/000088
}

\begin{abstract}
We investigated the effect of focus on the formation of $\mathrm{f} 0$ in two of the six tones of the Hà Nôi dialect of Vietnamese. This dialect contrasts six lexical tones, has no tone-sandhi, the language does not have focus markers and uses prosody exclusively to express pragmatic contrasts (Jannedy, 2007) by means of intonational emphasis in ways similar to English or German. To tease out the effect of focus on the duration and $\mathrm{f} 0$ of the level tone ngang and the rising tone sắc, identical short SVO-type utterances were elicited with a question-answer paradigm under three focus conditions (subject-, verb-, and object focus). Results indicate that the tone especially under subject- and verb- but also object focus shows an f0-excursion for the ngang tone and a scoop and sharp rise for sắc. Duration of the focused syllable also increases.
\end{abstract}

Key words: lexical tone, Vietnamese, focus, intonation

\section{Introduction}

Mon-Khmer languages are known for the complexity of their tone system: lexical contrasts are marked by tonal (pitch) as well as laryngeal features (Yip, 1995). This interaction of voice quality and lexical tone also characterizes Vietnamese (Brunelle, 2003). Several studies have explored the six-tone system of the northern (Hanoi) Vietnamese dialect and have established that there is a higher and a lower pitch register (Nguyễn and Edmondson, 1997). A graph of the shapes of the six lexical tones representative of the standard Hà Nội dialect can be found in Jannedy and Brunelle (2007). Three of the six tones are produced in a modal voice. In this work we will primarily describe the behavior of the rising tone sắc which canonically rises from the bottom of the pitch range to the top, and the neutral tone ngang which remains fairly stable in pitch throughout in it's canonical shape. (In the larger study, we also investigated the low-level tone huyền and all positional combinations of the three modal tones to get an understanding of their behavior under focus.)

Brunelle (2003) investigated the effect of coarticulation on neighboring tones in Hà Nội Vietnamese and found that progressive assimilation is stronger than anticipatory assimilation. Michaud and Vu (2004) propose based on their results that "[...] a stable correlate of emphasis is curve amplification, manifested [...] as an increased slope of F0 curve [...] or as F0 register raising." Jannedy (2007) tested whether native listeners of Hà Nội

ExLing 2008: Proceedings of 2nd Tutorial and Research Workshop on Experimental Linguistics, 25-27 August 2008, Athens, Greece 
Vietnamese were able to recover the information structure encoded in utterances recorded under different focus conditions and found that listeners were reliably able to identify subject-, verb- and object-focus utterances.

\section{Method}

\section{Corpus}

We constructed a corpus consisting of 21 simple SVO-sentences, all differing with regard to the lexical tones on the subject, verb and object. These sentences were recorded in a question-answer context under laboratory conditions. For an example, see Table1.

Table 1. Má lấy muối-Mother takes salt. - sắc sắc sắc.

\begin{tabular}{|l|l|l|l|}
\hline Chuyện gì thế? & What is happening? & {$[\text { Má lấy muối }]_{\mathrm{F}}$} & Sentential \\
\hline Ai lấy muối đấy? & Who takes salt? & {$[\text { Má }]_{\mathrm{F}}$ lấy muối } & Subject \\
\hline Má lấy gì đấy? & What is Ngà taking? & Má lâyy [muối $]_{\mathrm{F}}$ & Object \\
\hline $\begin{array}{l}\text { Má làm gì với } \\
\text { muối đấy? }\end{array}$ & $\begin{array}{l}\text { What is Mother doing } \\
\text { with the salt? }\end{array}$ & Má [lấy $]_{\mathrm{F}}$ muối & Verb \\
\hline Má làm gì đấy? & What is Mother doing? & Má [lấy muối $]_{\mathrm{F}}$ & VP \\
\hline
\end{tabular}

Only two of these tonal cofigurations are described in this paper. Four native Hà Nội Vietnamese speakers ( 3 females, 1 male) read the sentences 5 times as a reply to questions.

\section{Measurements}

All elicited utterances were constructed to contain three monosyllabic words with either the level tone ngang or the rising tone sắc on each word. The data was phonemically annotated in Praat (Boersma and Weenink, 2007) and the duration and F0-maximum was extracted for each phoneme. We also calculated the F0 at different time points (begin, 25\%, 50\%, and $75 \%$ into the vowel) within the tone bearing vowel in the word under focus. Also, time-normalized F0 contours were created via a script (Xu, 2007) and overlaid for easier visual comparison.

\section{Results and discussion}

The lines in the graphs below show time-normalized f0-trajectories for subject focus (black), verb focus (dark grey) and object focus (light grey) for the level tone ngang (left panels) and the rising tone sắc (right panels) for four speakers (F1-F3 and M1). Note that the language has complex vowel sounds much like diphthongs and that each vowel was preceded by a nasal or lateral consonant for easier tracking of the f0. 

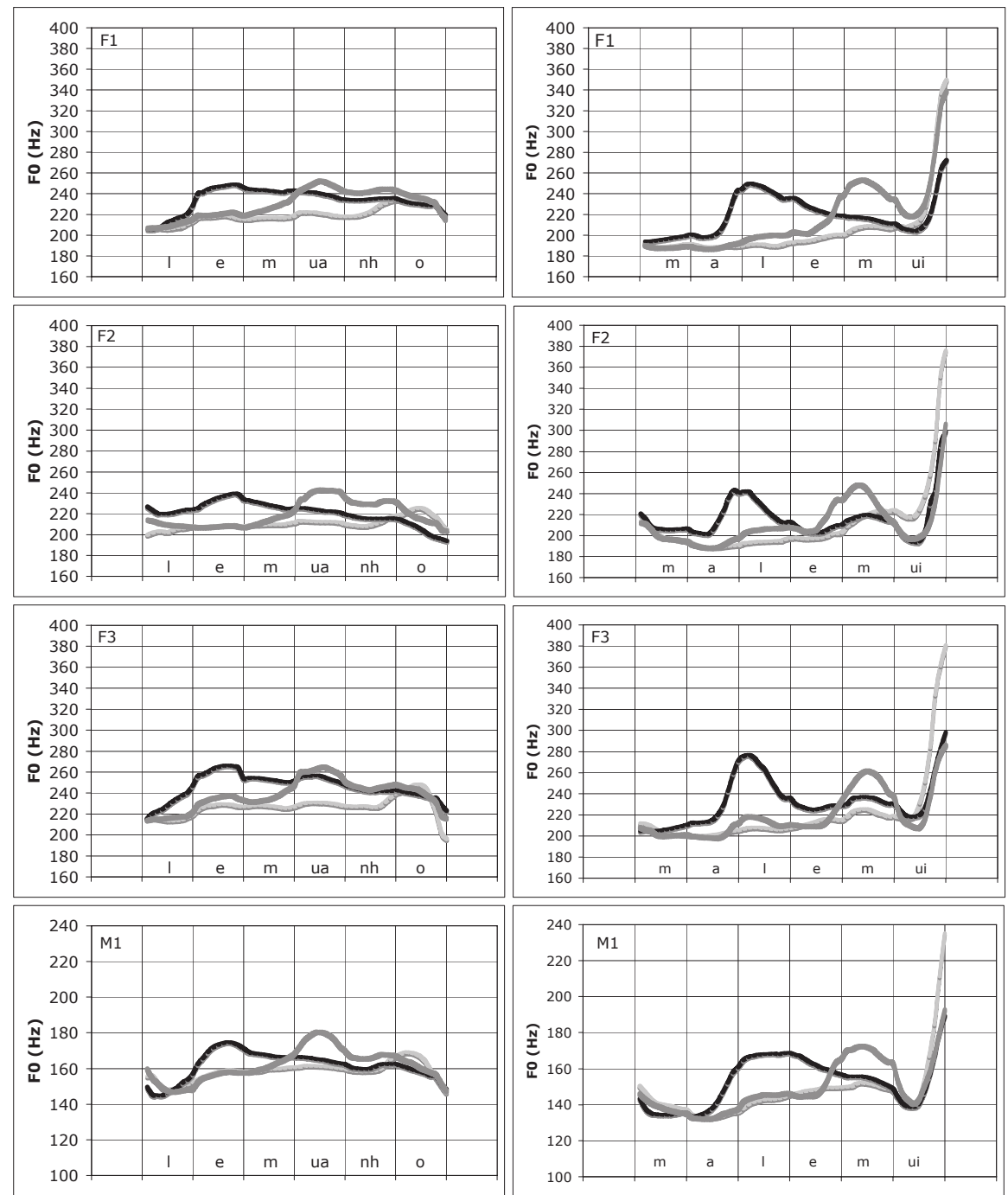

Figure 1. Time normalized F0-contours $(\mathrm{Xu}, 2007)$ for the level tone ngang (left) and the rising tone sắc (right) for three female (F1-F3) and one male speaker (M1).

We fitted linear mixed effects models with the measurements as the dependent variables, the Focussed Word as the fixed effect and Focus Condition and Speaker as random effects, separately for both tonal conditions. All main effects came out as significant $(p<.001)$. Table 2 shows the results of the post-hoc comparisons: for example, for the ngang tone, in the subject (verb and object) focus condition(s), we compared the values for the focused subject with the subjects in the $\mathrm{V}$ and $\mathrm{O}$ focus conditions (paradigmatic comparison). 
Table 2. Results of post-hoc Tukey-test of Subject-, Verb-, and Object focus conditions with $\mathrm{S}-, \mathrm{V}-$, and $\mathrm{O}$ in non-focus conditions in the same position.

\begin{tabular}{|c|c|c|c|c|c|c|c|c|c|c|c|c|}
\hline Tone & \multicolumn{6}{|c|}{ ngang (level) } & \multicolumn{6}{|c|}{ sắc (rising) } \\
\hline Foc & \multicolumn{2}{|c|}{ Subject } & \multicolumn{2}{|c|}{ Verb } & \multicolumn{2}{|c|}{ Object } & \multicolumn{2}{|c|}{ Subject } & \multicolumn{2}{|c|}{ Verb } & \multicolumn{2}{|c|}{ Object } \\
\hline no Foc & $\mathrm{V}$ & $\mathrm{O}$ & $\mathrm{S}$ & $\mathrm{O}$ & $\mathrm{S}$ & $\mathrm{V}$ & $\mathrm{V}$ & $\mathrm{O}$ & $\mathrm{S}$ & $\mathrm{O}$ & $\mathrm{S}$ & $\mathrm{V}$ \\
\hline F0-max & $* * *$ & $* * *$ & ** & $* * *$ & n.s. & n.s. & $* * *$ & $* * *$ & n.s. & *** & *** & ** \\
\hline Dur & $* * *$ & $* * *$ & $* * *$ & $* * *$ & $* * *$ & $* * *$ & $* * *$ & $* * *$ & $* * *$ & $* * *$ & n.s. & n.s. \\
\hline F0-start & $* * *$ & $* * *$ & n.s. & $* * *$ & n.s. & n.s. & $*$ & n.s. & $* * *$ & n.s. & n.s. & $*$ \\
\hline $\mathrm{F} 0-25 \%$ & $* * *$ & $* * *$ & n.s. & $* * *$ & n.s. & n.s. & $*$ & $*$ & $* * *$ & n.s. & n.s. & n.s. \\
\hline $\mathrm{F} 0-50 \%$ & $* * *$ & $* * *$ & $* *$ & $* * *$ & n.s. & n.s. & $*$ & $*$ & n.s. & n.s. & $* *$ & $* *$ \\
\hline F0-75\% & $* * *$ & $* * *$ & $* *$ & $* * *$ & n.s. & n.s. & $*$ & $* *$ & n.s. & n.s. & n.s. & n.s. \\
\hline & $* * *$ & & & $* *$ & $\overline{p<.0}$ & $*=$ & & & & sig & fica & \\
\hline
\end{tabular}

Results indicate that focus is expressed through $f 0$ and duration: duration increases in most cases significantly under focus. An Object in the O-Focus condition is less often found to be significantly different from objects in onfocus conditions. Duration and fo cues may be confounded by final lengthening and lowering effects. For ngang, the maximum f0-excursion is aligned with the tone bearing unit, while the rising tone shows much of its scooped shape under focus and utterance finally, but not medially unfocussed.

\section{References}

Boersma, P. and Weenink, D. 2007. Praat: doing phonetics by computer (Version 4.6.36) [Computer program]. (http://www.praat.org/).

Brunelle, M. 2003. Coarticulation Effects in Northern Vietnamese Tones. Proceedings of the 15th ICPhS. (http://aix1.uottawa.ca/ mbrunell/Research.htm).

Brunelle, M. and Jannedy, S. 2007. Social Factors in the Perception of Vietnamese Tones. Proc. of the 16th Intern. Congress of Phonetic Sciences, pp. 1461-64.

Jannedy, S. 2007. Prosodic Focus in Vietnamese. In Ishihara, S; Jannedy, S. and Schwarz, A. (eds.) Interdisciplinary Studies on Information Structure (ISIS), pp. 209-230, Potsdam University Press.

Michaud, A. and Vu, T.N. 2004. Glottalized and Non-Glottalized Tones under Emphasis: Open Quotient Curves remain stable, F0 curve is modified. Proceedings of the Speech Prosody 2004, pp. 745-748, Nara, Japan.

Nguyễn, V. L. and Edmondson, J. 1997. Tones and Voice Quality in Modern Northern Vietnamese: Instrumental Case Studies. Mon-Khmer Studies 28, 1-18.

Xu,Yi. 2007. http://www.phon.ucl.ac.uk/home/yi/downloads.html. 